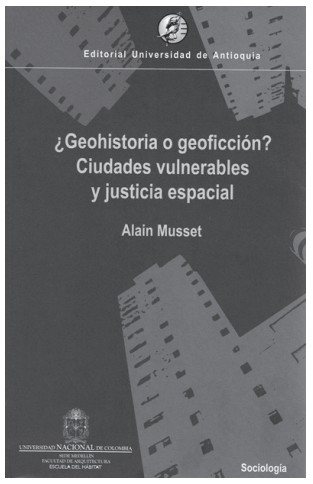

\title{
Alain Musset. ¿Geohistoria o geoficción? Ciudades vulnerables y justicia espacial
}

\author{
Medellín: Editorial Universidad de Antioquia, \\ 2009. 266 p.
}

\author{
Enrique Aliste Almuna ${ }^{1}$
}

Alain Musset $^{2}$ presenta su más reciente trabajo, que reúne una serie de investigaciones desarrolladas en los últimos años sobre el fenómeno urbano desde una mirada diferente y de gran riqueza conceptual. En este libro, su autor realiza una reflexión de conjunto en torno al devenir de las ciudades latinoamericanas con una pregunta implícita: ¿puede la ciencia ficción guiar una reflexión científica acerca de los fenómenos de representación de las ciudades? Desde allí surge la propuesta del concepto geoficción, que el mismo autor acuñara en 2005. Para ello, y tomando como referente la noción de imaginario y la geografía de las representaciones, el autor sostiene que es posible desarrollar un itinerario científico traspasando las barreras de las maneras clásicas de abordar las problemáticas que enfrentan las ciudades contemporáneas. Haciendo un parangón con la geohistoria que propusiera Fernand Braudel (Braudel, 1997), la geoficción puede entenderse como una mirada capaz de visualizar e imaginar derroteros científicos tanto transgresores como estimulantes para repensar los fenómenos de las ciudades actuales.

El libro se estructura en seis capítulos además de su introducción, donde aborda los temas relativos a Ciudad de México como laboratorio urbano de la crisis ambiental; los traslados de ciudades en la América hispá-

1 Departamento de Geografía, Universidad de Chile (Chile). E-mail: ealiste@uchile.cl

2 Geógrafo, Doctor en Geografía y Director de estudios en I'École des Hautes Études en Sciences Sociales (EHESS) de Paris. Autor de varios libros y nica; el tema de las comunidades étnicas, desigualdades sociales y la justicia espacial en Nicaragua; vida y muerte de las ciudades globales (de Ciudad de México a Coruscant); fragmentación espacial y segregación social en las ciudades de ciencia ficción y, por último, una mirada a los ciudadanos en tela de juicio (del Gueto de Venecia a los "sectores" de Angosta).

En cada uno de los capítulos de este libro el autor se plantea reflexiones orientadas a ver en el fenómeno espacial una oportunidad para el análisis desde la dimensión de los imaginarios en concordancia con los datos y sucesos registrados en fuentes de diversa naturaleza, que van desde los antiguos archivos de Indias, hasta la legislación local, la prensa, novelas, películas, cómics, entre otros. En síntesis, ofrece una amplia manera de mirar el fenómeno de la ciudad cuando esta se piensa desde diversos frentes, como el de los datos y pruebas provenientes de las investigaciones clásicas, así como aquellas que provienen desde dimensiones que responden a la creación artístico-cultural, que son, como bien el autor señala, también una manera de hacer y plasmar formas de representación que crean y producen espacio.

El interesante derrotero científico que propone Musset, rescata, desde la creación lite-

artículos en las áreas de geohistoria, geoficción, geografía social y estudios urbanos. Dirige diversos seminarios de investigación en la EHESS, donde destacan "Geografías del otro, otras geografías" y "Representar la ciudad". 
raria y fílmica, una manera de ampliar el horizonte explicativo al fenómeno de la ciudad. Cuando propone la geoficción, lo hace con el claro propósito de complementar lo tradicionalmente abordado en el estudio de las ciudades, dando desde acá una mirada a los procesos y a las consecuencias derivadas de esta nueva lectura. Musset habla de ciudades vulnerables y de justicia espacial, pero no en un sentido que solo se apega a lo que dicen los números o las tendencias estadísticas: hay vulnerabilidades e injusticias espaciales que se pueden descubrir a partir de las interpretaciones y las ficciones que se hacen de ciertos tipos de ciudades. En este sentido es de gran interés lo tratado para el caso de Ciudad de México, donde señala:

"Es a fines de los años ochenta, a raíz del terremoto de 1985, que esta imagen negativa de México se impone. Ya en 1986 la revista francesa 'Autrement' escribía 'México, entre esperanza y tormento'. El año siguiente, Miguel Messmacher publicaba un estudio que hacía hincapié en las disfunciones de una aglomeración gigantesca cuyo crecimiento no se podía controlar. Un año después, Claude BataiIlon y Louis Panabière, basados en datos estadísticos oficiales y en varios estudios de demografía prospectiva y comparativa, hicieron de la capital mexicana no solo la ciudad más grande del mundo, sino también la más contaminada"(Musset, 2009: $3)$.

De esta forma, Musset pone el acento en la dimensión de una ciudad que se construye también a merced de los imaginarios que le dan sentido y contenido, que incluso, con posterioridad, los datos pueden verificar y corroborar.

Desde otra óptica, lo hace también para explorar cómo desde la ciencia ficción las situaciones vinculadas a las realidades se solidifican en las estructuras imaginarias de la creación. Visitando el caso de numerosas obras de ciencia ficción, pasando por la ciudad de Coruscant de Star Wars, hasta la Metrópolis de Fritz Lang, sugiere la coincidencia que se da de la creación y reproducción de estructuras que encuentran su correlato en la realidad de numerosas ciudades de la actualidad. La lógica de la fragmentación social que se reproduce espacialmente, es algo que se da tanto en el ámbito de la ficción como en la realidad de la mayoría de las ciudades, en este caso, reales o de ficción.

Uno de los aspectos más interesantes en el trabajo de Musset, tiene que ver con la vasta bibliografía utilizada en sus análisis. La mezcla de literatura científica (que recurre a obras trascendentales para la geografía, como las de Bailly, Roncayolo, Lepetit, Reclus, Habermas, Sennett, Trochet, Braudel, Burgess, Castells, Duncan, Sassen, Soja, Weber, Harvey, Lefebvre, entre otras) con aquella proveniente de la ciencia ficción (destacando entre tantas a Asimov, Bergerac, Fresán, Monsivais, Jodorowsky, Volpi y Fuentes) y con un amplio complemento proveniente de archivos (donde resaltan el Archivo General de Indias de Sevilla, el Archivo Histórico de Santiago de Chile, el Archivo General de Centroamérica de Guatemala, entre otros) permite no solo una maravillosa aventura conceptual, sino que además resulta ser un gran estímulo a la exploración literaria de ficción no solo como un grato pasatiempo, sino que además, como un verdadero horizonte de exploración científica para el estudio de los fenómenos espaciales vinculados a la ciudad.

Respecto de lo específico tratado en cada capítulo, el primero de ellos, titulado La ciudad de México. Laboratorio urbano de la crisis ambiental, aborda cómo desde la historia, y en particular desde la geohistoria braudeliana, es posible dar una mirada en perspectiva a las condiciones ambientales actuales de la ciudad. Para dicho propósito, el autor releva una gran cantidad de información proveniente de los distintos archivos y crónicas hispánicas relativas a la conquista de América, para abordar desde una mirada crítica las decisiones tomadas en torno al modo de materializar el poblamiento de la ciudad. Así, analiza cómo el agua era un aspecto central en el modo de relacionarse con el medio, en el entendido de la ciudad lacustre. Este mismo aspecto, señala Musset, fue el que guió una serie de decisiones de gestión y ordenamiento del territorio para llevarlo a las formas españolas y criollas de relacionarse con el ecosistema, donde las condiciones lacustres eran vistas como una amenaza. Ello exige, por lo tanto, de un análisis de larga duración que permita entender la gestación de esta re- 
lación durante los siglos de ocupación española y luego criolla de la ciudad, que guiaron las decisiones de intervención del ecosistema mediante diversas obras hidráulicas, las que en su contexto respondían a criterios de época pero con el tiempo fueron paulatinamente sembrando la situación de vulnerabilidad ecológica actual de la ciudad.

El capítulo 2, Los traslados de ciudades en la América hispánica: territorios en riesgo, sociedades vulnerables, realiza una extraordinaria revisión de los traslados de ciudades americanas entre los siglos XVI y XX. En este acápite, Musset señala que la noción de vulnerabilidad es la que moviliza desde la Conquista española y hasta mediados del siglo XX la mayor parte de los traslados de ciudades en América Latina, Ilegando a un registro de más de 270 traslados, considerando en ello que muchas ciudades fueron reasentadas más de una vez. El autor sostiene que para comprender el análisis propuesto es preciso entender el marco de referencia que entrega la geohistoria, a fin de aproximarse a una geografía de larga duración que otorgue bases para la comprensión de las sociedades contemporáneas y su relación con el entorno en que habitan. Entre los casos analizados, se puede destacar el de las ciudades de Puebla (México), Santo Domingo (República Dominicana), Chillán (Chile), Concepción (Chile) y Antigua Guatemala (Guatemala), por señalar algunas. Su análisis lo hace inicialmente en función de elementos cuantitativos, entre los que está la amplitud (distancia), densidad, ritmo y frecuencia de los traslados en un contexto regional, para dar paso luego a una fase interpretativa basada en el enfoque geohistórico, donde analiza lo que significa la fundación de ciudades españolas en el contexto natural americano, utilizando el enfoque del riesgo, los discursos y las prácticas asociadas.

El capítulo 3, León-Sutiaba (Nicaragua): comunidades étnicas, desigualdades sociales y justicia espacial, apunta al estudio de un caso particular en lo que se refiere a la justicia espacial. En su análisis, resalta que el tema está más próximo a las materias de gestión urbana y el marco teórico de las democracias participativas. Con dicho propósito, el autor comienza por contextualizar los argumentos conceptuales provenientes desde el estudio de las condiciones de justicia es- pacial tratado a partir de los años setenta del siglo XX, destacando los trabajos de Harvey, Young, Soja y Reynaud. Desde allí, sitúa el punto de partida para un análisis de la conflictiva relación existente entre el barrio indígena de Sutiaba y la ciudad española de León ${ }^{3}$, en Nicaragua. Observaciones de campo y el apoyo en datos empíricos como los censos de comercio, permiten evidenciar las fuertes diferencias que pueden visualizarse a partir de la identificación de un límite entre ambos sectores, dando espacio a la noción de justicia espacial que interesa destacar al autor, pasando por reflexiones en torno a decisiones políticas, acciones de intervención sobre el espacio y discursos, entre otros.

El capítulo 4 se titula De México a Coruscant (Star Wars): vida y muerte de las ciudades globales, y en él, el autor enfatiza en el estudio de las representaciones sociales para la comprensión de las relaciones urbanas (Roncayolo, 1997). En el inicio del capítulo se hace una importante advertencia al señalar que al enfrentar este tema, el autor debe situarse en la frontera entre lo psicológico y lo social. De esta forma, Musset va a través de lo que significa enfrentar a la ciudad imaginaria, y por ello, señala, es necesario comprender que esta es mucho más que un mero juego intelectual y es en definitiva, también, una exploración con carácter científico. Su paso por los modos de mirar a una ciudad real desde las novelas de ficción, va contorneando lo que significa el otorgarle sentido y significado a universos más allá de lo real pero que están inexorablemente basados en situaciones de gran realismo. Así realiza un interesante viaje exploratorio por la ciudad de Star Wars, Coruscant, en donde, como bien él señala, es la:

“(...) ciudad sincrética que abarca todos los temas conflictivos planteados por la problemática urbana contemporánea: tensiones entre comunidades étnicas, exclusión económica, segregación espacial, pérdida del vínculo social, desaparición de los espacios públicos, contaminación, violencias urbanas (...) [convirtiéndose] en el epítome de la ciudad global potente

3 Trasladada en 1610 
y sin embargo vulnerable, sede de una sociedad urbana brillante, pero sumamente injusta" (Musset, 2009: 96).

La ciudad capital de la galaxia, señala Musset, sede de todos los poderes, no se diferencia mayormente de la ciudad global que describe Saskia Sassen (1991) en su Global City (potencia económica, política y cultural, que no necesita producir físicamente pues produce decisiones y servicios). Esta vasta exploración de la construcción de símbolos sobre la ciudad, pasa también por una interesante revisión de los conceptos fundadores de deterioro de lo que significa la imagen de la ciudad y de lo urbano. Así, el pensamiento de Thoreau y Emerson es visitado para entender también la construcción de una imagen negativa del ambiente urbano, proveniente ya de ideas propias de la segunda mitad del siglo XIX, asociado posteriormente con ideas vinculadas a las patologías urbanas, la ciudad criminógena y las ideas apocalípticas sobre la urbe.

El capítulo 5, titulado Fragmentación espacial y segregación social en las ciudades de ciencia ficción, siguiendo un poco con la línea iniciada en el capítulo anterior, pone su énfasis esta vez en las nociones de segmentación y fragmentación urbana, como un tema cada vez más importante para las ciencias sociales contemporáneas. Su análisis comienza revisando lo que significó el aporte de la Escuela de Chicago en lo que se refiere a estudios de ecología urbana asociados a formas de segregación de los espacios urbanos, lo que con el tiempo se ha ido actualizando y complejizando con nuevas observaciones a este proceso. Musset señala que los autores de ciencia ficción no han hecho otra cosa que repetir patrones sociológicos en las relaciones espaciales y, a partir de ello, poner en evidencia las distancias sociales existentes. Podría señalarse que lo que hace Musset en este capítulo es, a partir de una revisión exhaustiva de ciertos patrones que son utilizados en la ciencia ficción, analizar el correlato con la realidad de las ciudades actuales (principalmente de América Latina) en lo que se refiere a condiciones sociales, existencia de barrios, lugares marginales, relaciones centro periferia y ciudades que coexisten en un mismo espacio, entre otras.
El capítulo 6 y final se titula Del gueto de Venecia a los sectores de Angosta: Ios ciudadanos en tela de juicio. En este capítulo, lo que explora Musset es profundizar en torno al sentido y vínculo que hay entre la geoficción y la geohistoria braudeliana. Tal como lo señala al inicio del capítulo, "la geoficción no es sino la parte prospectiva de la geohistoria" (Musset, 2009: 160). Destaca además un elemento que merece también ser reproducido textualmente: "Pero ambas persiguen el mismo propósito [geoficción y geohistoria]: entender tanto las realidades como las representaciones de las sociedades contemporáneas" (Musset, 2009: 160). De esta forma, avanza en el análisis de las morfologías presentes tanto en ciudades de la ciencia ficción como en una serie de ciudades latinoamericanas y asiáticas. Y una morfología no solo arquitectónica, sino que además y por sobre todo, socioespacial. En tal sentido, por ejemplo, destaca el papel que el miedo juega en la configuración y articulación/desarticulación de espacios urbanos, tanto en la ciencia ficción como en las ciudades de la actualidad. Lo que en la Delta City de Robocop se veía como argumento de la ficción, en ciudades tradicionales ya era un elemento central que las caracterizaba, como por ejemplo las murallas (observación en la que coinciden desde Weber hasta Roncayolo y Foucault). Guetos simbólicos, guetos voluntarios, guetos obligatorios y guetos mentales son explorados por Musset para pronunciarse finalmente respecto de lo que él llama la geografía urbana del miedo. Allí, destaca que si bien el miedo ha sido un elemento presente en la sociedad urbana desde el siglo XVIII, cuando se comienzan a derrumbar las murallas de las ciudades fortificadas de Europa, a la vez su relato fascina; no en vano, como lo indica, los programas que destacan la imagen del crimen en vivo tienen tanto éxito en Estados Unidos y América Latina. Ello articula una forma espacial y un modo de vivir el espacio que, de ese modo, genera a su vez nuevas formas y relaciones espaciales. De la acción de las pandillas a la consolidación de los barrios cerrados, Musset realiza un relato en perspectiva de este proceso actual.

Finalmente, uno de los temas relevantes que expone Musset, si bien no a modo de conclusión pero bien podría entenderse como un corolario posible de esta obra, es el 
punto referido a una ciudad sin ciudadanos. En efecto, y si bien se refiere puntualmente al capítulo final, se plantea el tema de la desaparición de los espacios públicos en las ciudades de ciencia ficción, como señal de una ciudad que llega a su fin en tanto órgano político. Viendo los paralelos entre realidad y ficción, y considerando el estrecho vínculo sociológico que existe entre ambas, vale la pena preguntarse por el papel de ciudadano en una ciudad que va mutando velozmente en una transformación rotunda del sentido que los espacios públicos tuvieron en un momento de la historia, y en donde el sentido de la ciudadanía por lo mismo, tenía un rol particular. En los nuevos espacios, como bien se lo cuestiona Musset, cabe la pregunta " ¿de qué soy ciudadano?" (Musset, 2009: 199).

\section{Referencias bibliográficas}

BRAUDEL, F. Les ambitions de l'histoire. Paris: Éditions de Fallois, 1997.

RONCAYOLO, M. La ville et ses territoires. Paris: Éditions Gallimard, 1997.

SASSEN, S. The global city: New York, London, Tokio. Princeton: Princeton University Press, 1991. 